MATEC Web of Conferences 9, 03006 (2013)

DOI: $10.1051 /$ matecconf/20130903006

(C) Owned by the authors, published by EDP Sciences, 2013

\title{
Façade fires in Swedish school buildings
}

\author{
Nils Johansson ${ }^{1}$, Patrick van Hees ${ }^{1}$, Margaret Simonson McNamee ${ }^{2}$, \\ Michael Strömgren ${ }^{2}$ and Robert Jansson ${ }^{2}$
}

\author{
${ }^{1}$ Department of Fire Safety Engineering and System Safety, Lund University, Sweden \\ ${ }^{2} \mathrm{SP}$ Technical Research Institute of Sweden
}

\begin{abstract}
Fires outside school buildings caused by arson are a major problem in Sweden. The initial fire source can involve rubbish or other types of combustibles that can be found at or sometimes brought to the school. As the external fire develops the flames will extend along the façade. If the building is a one-story building, which is a common construction in Swedish school buildings, the fire can spread to the attic and further on to the rest of the building.

A large research project was initiated in 2008 by the Swedish Fire Research Board in order to reduce the number and consequences of arson fires in school buildings. In this paper an evaluation of some technical systems that can be used to mitigate consequences of exterior fires is presented. The evaluation includes a literature review, experimental studies and a cost-benefit analysis. The study showed that some systems have clear cost-benefit advantages for the protection of school buildings in places where a high fire frequency can be expected.
\end{abstract}

\section{INTRODUCTION}

Between one and two school fires occur in Sweden every day and in most cases arson is the cause of the fire. These fires rarely lead to any fatalities or injuries. Consequently, they are not considered to be a life safety problem. However, the yearly cost is approximately 50 million euros, which is approximately $10 \%$ of the total cost of fires in buildings in Sweden. This is significant compared to other types of occupancies in Sweden. For this reason, the Swedish Fire Research Board (Brandforsk) launched a multidisciplinary umbrella project in 2008 [1] with the aim to reduce the number of arson fires in Sweden in the long-term. SP Fire Technology started the umbrella project with an exploratory study where it was concluded that the problem should be addressed broadly and include research groups from both social and technical sciences. In 2009 the research program was initiated with some smaller initial studies that were followed by several 3-year long projects in 2010. Several Swedish universities and research institutes have been involved in different projects.

In one of the initial projects, a case study of almost 60 school fires was conducted [2]. The case study consisted of a meta-analysis of fire investigation reports that was supplied by the Swedish Civil Contingencies Agency (MSB). A number of technical deficiencies in the current fire protection of school buildings (schools and pre-schools) were identified in the study. Examples of the identified deficiencies include: lack of detection systems and automatic alarm systems, poor constructions and insufficient or malfunctioning fire compartments. Four typical fire scenarios, which comprised a majority of the studied fires, were also identified in the study. The case study was complemented with a literature survey [3] in order to further describe and quantify these initiating fires.

Studying the most severe and costly fires it became clear that exterior fires that start close to the school buildings façade were overrepresented. For example, in 2009 the total cost of the six most expensive school fires was nearly 50 million euro and at least five of these started with an exterior

This is an Open Access article distributed under the terms of the Creative Commons Attribution License 2.0, which permits unrestricted use, distribution, and reproduction in any medium, provided the original work is properly cited. 


\section{MATEC Web of Conferences}

fire. Consequently, in order to reduce the overall cost of school fires it is important to reduce the consequences of these fires or even to prevent this particularly fire entirely.

In this paper, a summary of the research conducted in regard to exterior fires in school buildings is presented. The aim of this research has been to evaluate different technical systems that can be used to mitigate the consequences of exterior arson fires. There are several different types of technical systems that can be used for this purpose, but no systematic study of the: function, efficiency and economics of installing these systems have been conducted until now. The findings in the entire project have been presented in previous publications [1-6] but this paper gives a summary of the results in regard to exterior fires.

\section{EXTERIOR FIRES IN SCHOOL BUILDINGS}

Most of the severe and costly school fires in Sweden start, as mentioned, outside the building close to the façade. The initial fire is often set in some rubbish that might be soaked in a flammable liquid, but can also involve a small car or moped, which will give a larger potential heat release rate (HRR). The fire can develop in both these exterior fire scenarios and the flames extend along the façade of the building. If the building is a one-story building, which is a common construction in Swedish school buildings, the fire can spread to the attic and further on to the rest of the building through ventilated eaves. These attics are often constructed without insulation and with no or very limited fire separation down to the space below. The roof construction is often made of wood.

In the current Swedish building code [7] it is prescribed that attics and ceiling spaces should be divided into spaces of maximum $400 \mathrm{~m}^{2}$ with fire walls rated EI30 and spaces of maximum $1200 \mathrm{~m}^{2}$ separated with fire walls with EI60 rating. The current building code also states that if there is a fire barrier between the attic and the space below the risk of fire spread through the eaves shall be limited. However, many existing buildings in Sweden do not have any fire separation in the attic or between the attic and the space below.

If the attic is not divided into fire compartments, the fire can spread over the entire building rapidly due to the low height of the space and the availability of combustible materials. If fire compartmentation is lacking or insufficient between the attic and the space below, the fire will eventually spread to the classrooms. In the cases where there is no detection system on the façade or in the attic, the fire will first be detected when smoke reaches the classroom areas. This means that large parts of the school will be heavily damaged even before the fire service is alerted. This type of fire development was found to be overrepresented in the most severe fires in the case study [8].

\section{TECHNICAL SYSTEMS}

There are several different types of technical systems that can be used to mitigate the consequences of exterior fires. An inventory and literature review of such systems has been conducted in the project [8]. The inventory consisted of interviews with representatives from 13 Swedish municipalities along with studies of fire protection documentation of school buildings. The inventory provided an overview of fire protection systems used to prevent arson in schools and pre-schools. The full list of technical systems and other measures is provided in a project report [8]. Here a description of the most essential and/or common systems is given.

\section{Linear heat detectors}

A maximum temperature linear detector and a differential linear heat detector have been studied in the project. The maximum temperature linear detector is composed of two copper-coated steel wires that are individually insulated with a heat-sensitive polymer. The conductors will create a short circuit and detection will take place when the polymer insulation is heated to a specified temperature [5]. 
The differential linear heat detector consists of a very thin sealed steel tube connected to a pressure sensor [8]. Detection will take place when the tube is heated and the sensor registers the rapid increase in pressure. Both types of linear heat detectors are usually placed on or directly below the eaves of onestory school buildings and they will detect a growing fire along the entire length of the cable and the detectors can be connected to an existing automatic fire alarm system. SP Fire Technology has provided advice on how to install these types of cables based on a series of experiments [9].

\section{Smoke detectors}

One-storey school buildings in Sweden are often fitted with small uninsulated attics that are naturally ventilated with openings in the eaves. This means that smoke will flow into the attic from the outside and smoke detectors can be placed in these types of attics to detect the smoke [8]. The smoke detectors can be connected to an existing automatic fire alarm in the building. There are no specific advice, in regard to this specific type of application, on how the detectors should be placed and the spacing between detectors in Sweden.

\section{Thermo-sensors}

The thermo-sensor uses thermal imaging for infrared surveillance and can be used to detect people and against suspicious actives around buildings [8]. It is problematic to obtain permission to use normal closed circuit camera surveillance (CCTV) located near public buildings in Sweden from regulatory agencies due to issues of privacy. However, with thermo-sensors the issue of privacy decreases because it is hard to identify individuals from thermal images. Therefore, it has been possible to obtain necessary permits to install thermo-sensors around school buildings. The thermo-sensors are usually connected to a security company. If a sensor detects suspicious activity, personnel can be alerted to take action accordingly. Such actions can be to dispatch security guards to the scene or to scare of the potential perpetrators with a voice message.

\section{Fire Barriers}

There are several passive fire protection measures that can be considered when designing protection against the studied type of fire. The focus in this paper is to protect the eaves in order to prevent fire spread into the attic and two different methods to do this are described here. In the first method the eaves are protected with non-combustible cement-based boards and the ventilation openings in the eaves are replaced with other ventilation solutions in the attic. In the second method, the eaves are protected with incombustible cement-based boards and the ventilation openings in the eaves are kept intact but provided with an intumescing system that will close the opening in case of fire. This second method is more expensive but can be applied in an existing building without changing the ventilation conditions of the attic much.

\section{EVALUATION OF THE TECHNICAL SYSTEMS}

The technical systems have been evaluated in regards to performance and how cost effective each of the systems is. The evaluation of the performance of the systems has been done with the help of a literature review [8], a series of experiments and a cost-benefit analysis.

\section{Experiments}

The maximum temperature linear detector was tested in small-scale setup in order to study how the linear heat detection cable can be modelled with the computer program FDS [5]. In that study it was found 


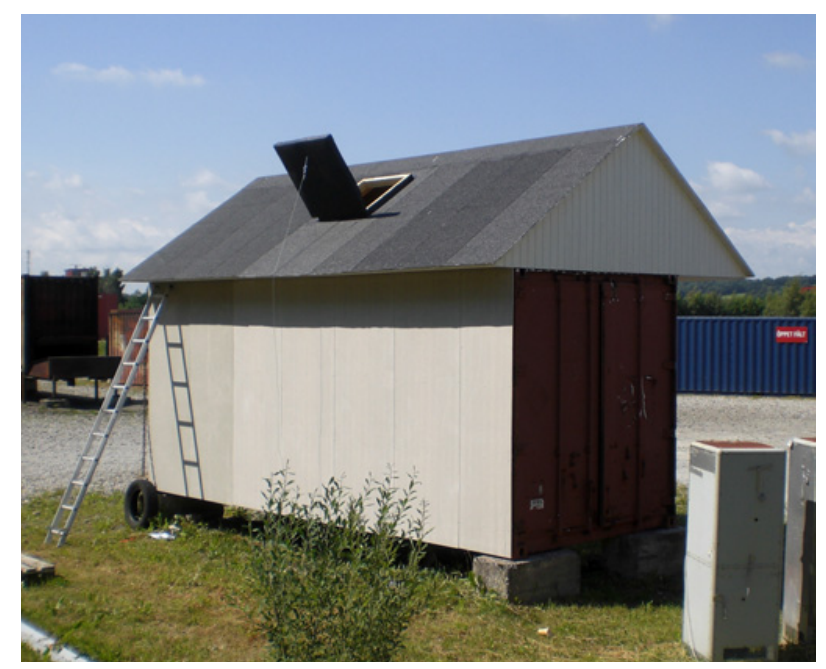

Figure 1. Experimental setup.

that a sub-model in FDS that is based in the THIEF cable model, could be used to simulate detector cables in a controlled environment. However, the exterior fire is subjected to the outside environment and the weather conditions will likely have a major impact on the detection time. In order to estimate the benefit of installing different technical systems it is necessary to have an idea of the detection time for realistic outdoor scenarios and that is hard to get from computer simulations. A series of real-scale outdoor experiments were therefore conducted.

\section{Real-scale outdoor experiment}

More than 20 different experiments were performed in a one-story mock-up building consisting of a 20 -foot container fitted with a roof and a small attic (see Figure 1) [4, 10]. Two types of façade cladding were used in the experiments: a non-combustible cement based board and a wooden façade painted with water based paint. The fire source was placed $2.5 \mathrm{~m}$ below the eave on one side of the building. The eaves were $300 \mathrm{~mm}$ wide and the ventilation opening in the eave was $30 \mathrm{~mm}$ or $60 \mathrm{~mm}$. The attic was $3.5 \mathrm{~m}$ wide, $6 \mathrm{~m}$ long and the distance from the ridge to the floor of the attic was $1.2 \mathrm{~m}$. All experiments were ignited at the same location on the facade and the wooden façade was replaced between tests.

In all the experiments, a maximum temperature linear detector and a differential linear heat detector were placed on the façade and smoke detectors were placed in the attic space. The smoke detectors were placed as high as possible in the attic, directly above the fire source and displaced $2.5 \mathrm{~m}$ laterally from it. Temperatures were measured with thermocouples at several places on the facade and in the attic. In two of the experiments a graphite based intumescent system was installed in the eaves in order to prevent the fire from spreading into the attic. Heptane was used as the fuel in all the experiments and four fire sizes of ignition sources were used: $260,140,65$ and $8 \mathrm{~kW}$. A load cell was used to monitor the mass loss from the fuel. A more detailed description of the experiment and different parameters is given in previous publications $[4,11]$.

The detection time for the different systems varied considerably (see Table 1) and it was not possible to see any effect of the facade type or ventilation opening on the detection time. However, there was a trend indicating that a higher heat release rate provides for a faster detection. Detection times for the linear heat detection cable and the differential linear heat detector were consistent with results from previous studies conducted at SP Fire Technology [9]. 
$1^{\text {st }}$ International Seminar for Fire Safety of Facades, Paris (France), 2013

Table 1. Recorded time to detection for the different technical systems [4].

\begin{tabular}{|l|l|l|l|l|}
\hline \multirow{2}{*}{ Technical system } & \multicolumn{3}{|l|}{ Detection time (sek) } & \multirow{2}{*}{ Number of tests } \\
\cline { 2 - 5 } & Min & Max & Mean & \\
\hline Linear heat detection cable & 64 & 400 & 179 & 9 \\
\hline Differential linear heat detector & 16 & 27 & 22 & 4 \\
\hline Smoke detector placed in attic 1 & 88 & 478 & 162 & 21 \\
\hline Smoke detector placed in attic 2 & 77 & 316 & 168 & 18 \\
\hline
\end{tabular}

Table 2. Estimated detection time and detection frequency in the tests [4].

\begin{tabular}{|l|l|l|}
\hline Technical system & Detection time (sek) & Detection frequency \\
\hline Linear heat detection cable & 180 & $43 \%$ \\
\hline Differential linear heat detector & 30 & $19 \%$ \\
\hline Smoke detector placed in attic & 180 & $100 \%$ \\
\hline
\end{tabular}

The differential linear heat detector discovered the fire in only 4 of the 21 tests (19\%) (see Table 2), while the linear heat detection cable discovered the fire later but in 9 tests (43\%). The smoke detector closest to the fire (detector 1) discovered all fires and the other smoke detector (detector 2) discovered all but two fires. It must be remembered that the fire size was constant and if it had been allowed to grow bigger all systems would probably have detected the fire at some point. For instance a sudden increase of temperature is required for the differential linear heat detector to detect a fire and in some of the tests the increase in temperature was too low which resulted in the system not being able to detect the fire. Based on experimental results (see Table 2), the generic detection times in Table 2 were estimated for further evaluation of the systems using cost-benefit analysis.

The thermo-sensor could also be used to detect an exterior fire but it was not evaluated in the experiments since these sensors register heat from people moving around a building and can give an alarm before a fire is lit. Accordingly, based on this information the detection time for thermo-sensors was set to 0 seconds.

A graphite based intumescent system was placed in the eaves during two of the tests. This system did not work as intended in any of the tests, which was was probably due to that the temperatures at the eaves were too low for the intumescent reaction to be initiated. Still, a hypothesis was formed that this type of intumescent system might not work as intended when heated more slowly than the standard heating curve, which it is tested for. Support for this hypothesis was also found in previously performed experiments at SP Fire Technology [13]. Therefore, an additional experimental series was conducted where a small-furnace furnace was used to test a graphite based intumescent system under a range of different heating conditions [12].

\section{Small-scale tests of an intumescent system}

Standardized classification methods according to a certain fire rating include rapid heat exposure of the product that is tested and this might not always be the worst-case scenario for the product. For this reason is it important to investigate how a graphite based intumescent system, intended for cavities, functions when subjected to heating conditions that differ from that in EN 1366-4 [12]. Two different experimental setups, a cone calorimeter (ISO 5660) and a small-scale furnace (SP Fire 119), were used in the experiments.

In the Cone Calorimeter experiment four different heat fluxes were used: $10,15,20$ and $25 \mathrm{~kW} / \mathrm{m}^{2}$. A $0.25 \mathrm{~mm}$ thermocouple (Type $\mathrm{K}$ ) was placed in the centre of the sample in order to obtain an estimate of the temperature at the sample surface. Each test lasted for 8 minutes and was video recorded. The time to reaction was estimated visually. The experiment had two purposes. The first was to gain an 


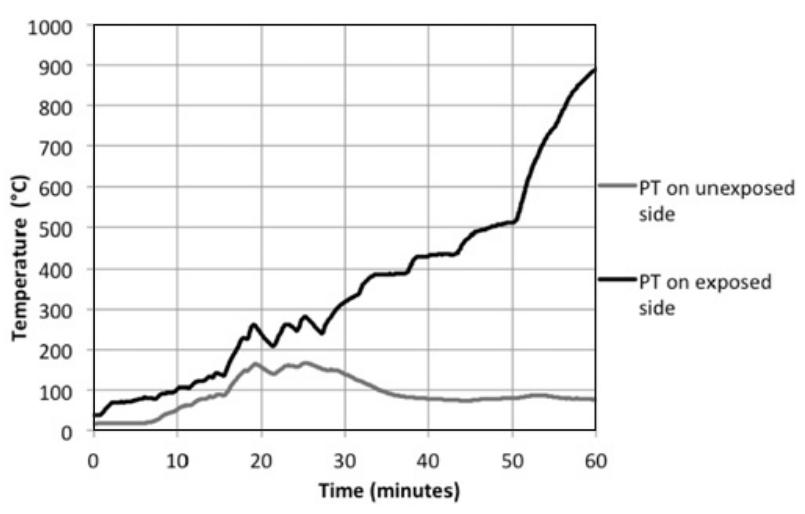

Figure 2. Plate thermometer temperature on exposed and unexposed side of fire stopper in test 3 [12].

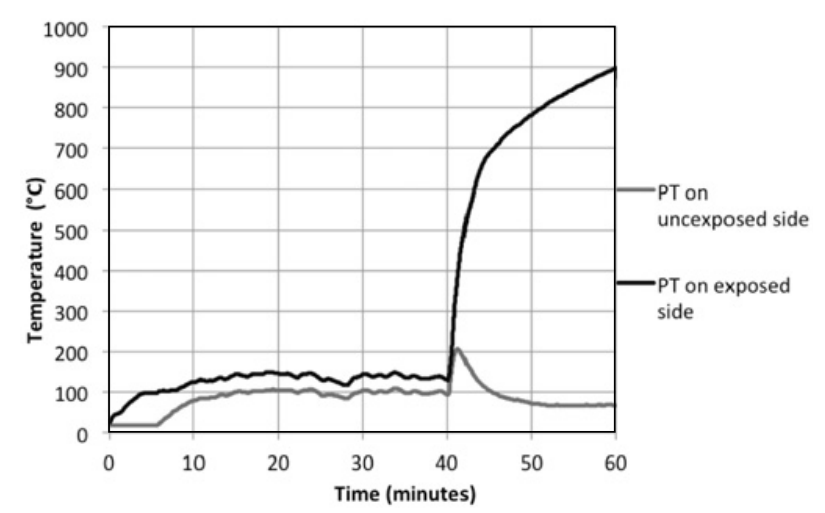

Figure 3. Plate thermometer temperature on exposed and unexposed side of fire stopper in test 4 [12].

understanding of how the graphite behaves when subjected to different heating conditions and whether this influences the expansion of the material. The second purpose was to see whether a single critical temperature at which the tested graphite starts to expand could be identified.

In the small-scale furnace tests according to the method SP Fire 119, the intumescent system was placed on the top of the furnace in a slot $(0.3 \mathrm{~m}$ long and $0.04 \mathrm{~m}$ wide) between blocks of lightweight cellular concrete in order to give a representation of a vertical cavity in an eave. Eight different tests were performed where the temperature in the furnace was controlled and kept at different pre-defined heating conditions. This meant that the intumescent system was subjected to both realistic and extreme heat exposures in the furnace tests in contrast to the thermal exposure and pressure difference specified in tests according to the linear joint seals standard, EN 1366-4 [14]. The experiments in the furnace showed that the intumescent commenced expanding when the temperature was approximately $180^{\circ} \mathrm{C}$. This temperature seemed to be rather independent of the incident heat flux in the Cone Calorimeter, while the expansion rate was clearly dependent on the incident heat flux. The system studied in the furnace was seemingly not affected by being pre-heated or not and whether the system was wet or dry. The graphite expanded sufficiently to give the same protection as when subjected to a heat exposure similar to the ISO 834 fire curve [15]. Some of the results from the small-scale furnace are presented in Figures 2 and 3. 
$1^{\text {st }}$ International Seminar for Fire Safety of Facades, Paris (France), 2013

Figure 2 shows results from the test where the temperature in the furnace (grey line) increased $10^{\circ} \mathrm{C} / \mathrm{min}$ during the first $50 \mathrm{~min}$, then a more rapid increase $\left(40^{\circ} \mathrm{C} / \mathrm{min}\right)$ during the final 10 minutes. When the temperature in the furnace reached about $180^{\circ} \mathrm{C}$ the measured temperature above the intumescent (black line) starts to level off. This indicates that the intumescent has expanded and sealed the opening. Figure 3 illustrates how the temperature in the furnace (grey line) was kept steady at about $150{ }^{\circ} \mathrm{C}$ for 40 minutes at which point the temperature was rapidly increased approximately according to the standard time temperature fire curve. The temperature on the unexposed side (black line) initially follows the temperature in the furnace, but when the temperature increases after 40 minutes the intumescent system expanded and the opening was closed, resulting in a decrease in temperature on the unexposed side.

The results of these experiments indicate that this type of intumescent will expand sufficiently when heated to other conditions than prescribed in classifications methods like EN 1366-4. However, it must be stressed that these results are only valid for the system studied and the specific experimental situation. Future research is needed to study how other types of intumescing fire protection systems work when subjected to realistic fire environments.

\section{Cost-Benefit analysis}

In the final part of the project a cost-benefit analysis was conducted $[4,11]$. The following six different technical systems and/or methods were studied:

- Maximum temperature linear detector

- Differential linear heat detector

- Smoke detector placed in a uninstalled ventilated attic

- Thermo sensor

- Protection of eaves with incombustible boards and an alternative ventilation of the attic

- Protection of eaves with incombustible boards and an intumescing system that will close the opening in case of fire.

Two fictive but typical school buildings were used as benchmark cases in the cost-benefit analysis. Both buildings consisted of a one-storey construction with a non-insulated attic under a gable roof. The first building was a typical pre-school building with a floor area of $1200 \mathrm{~m}^{2}$ with no special fire safety measures to protect the school from loss of property in case of fire. The second building was a school building covering $5000 \mathrm{~m}^{2}$ and equipped with an automatic fire alarm with smoke detectors placed in the school.

Estimating the costs of the systems

Information regarding costs of the different systems was retrieved from consultants, manufacturers and contractors. The initial investment costs (e.g. cost of planning, materials and labour) and future costs (e.g. cost of repairs, service, running and maintenance) were included in the cost estimate of each system. All systems were assumed to have a lifetime of 20 years and the net present value method was used to take into account that costs occur at various times during the economic lifetime of the system.

The costs used in the project must be regarded as rough estimates, because they will vary between countries, manufacturers and contractors. Additionally, certain technical systems may have a shorter lifetime than others. The costs for de-commissioning a system have not been considered in this analysis although this could be included if deemed necessary or important. A more detailed description of how the costs have been estimated is available in a project report [11]. 


\section{MATEC Web of Conferences}

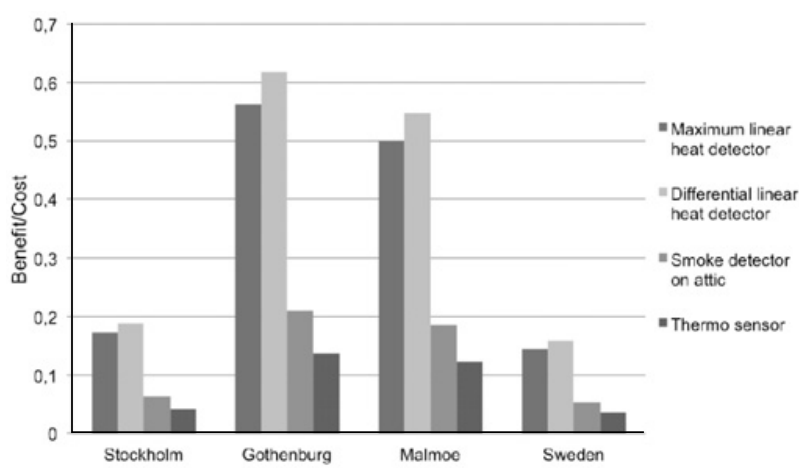

Figure 4. The cost-benefit ratio of the four studied detection systems in reference building 1 in the three major cities in Sweden and on a national level.

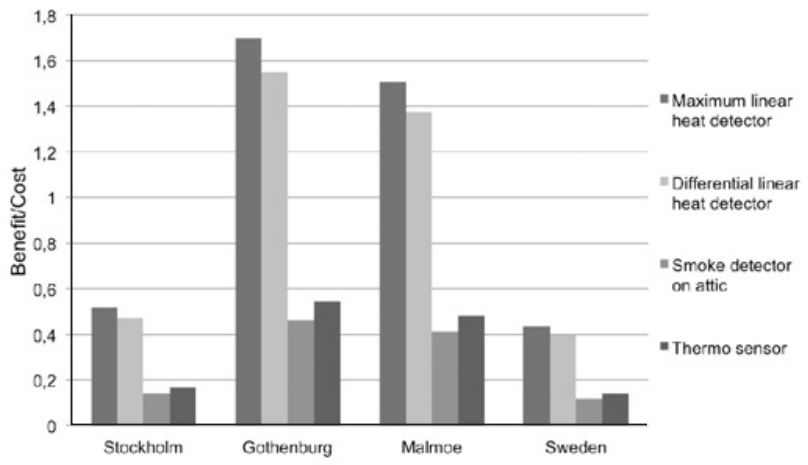

Figure 5. The cost-benefit ratio of the four studied detection systems in reference building 2 in the three major cities in Sweden and on a national level.

\section{Estimating the benefit of the systems}

The method of how to estimate the benefit of each system varied between the different types of systems. For the detection systems a value of the money saved per second and the time saved, e.g. the difference between the detection times in the benchmark case and for the case when a technical system is installed, was used to estimate the benefit. For protection of the eaves the benefit of taking measures was derived by comparing the estimate expected cost of a fire including measure with the expected cost of the same fire for the benchmark case.

The reliability of each system was accounted for in the estimate of expected benefit. Estimates of the reliability of the different systems were made based on available literature and the previously mentioned experiments. A more detailed description of how the benefit of each system has been estimated is available in a project report [11].

\section{Cost-benefit ratio}

A useful way to present results from a cost-benefit analysis is cost-benefit ratios. By dividing the expected benefit with the estimated cost for all the six studied systems were such ratios derived. Ratios over 1 are beneficial and the higher the ratio, the more beneficial is the system. Results for the four detection systems are presented in Figure 4 and Figure 5. 
It is important to stress that the analysis is object specific since the results are linked to the two studied reference buildings. That there is a difference in result between the two reference buildings is clear from Figures 6 and 7. It will not be beneficial to install any system in the smaller building because the expected loss is too low to motivate any of the technical systems. The linear heat detectors are superior to the other systems. Even though the differential linear heat detector has been assumed to have a much lower detection time (see Table 2) the differences between the systems are small, this is due to the fact that the linear heat detection cable is less expensive. Furthermore, the study showed that some systems have clear cost-benefit advantages for the protection of school buildings in places with high fire frequency like Gothenburg and Malmoe but not on a national level. The results and method used can be used as one basis for determining which system to invest in.

There is a high degree of uncertainty in the results and a sensitivity analysis has been performed in order to study how sensitive the result is to some of the uncertain parameters. More information on the sensitivity analysis can be found in the project report [11]. General conclusions from the cost-benefit analysis should be treated with care. The method is best suited for application on a case-by-case basis, where the object specific factors are taken into account.

\section{CONCLUSION}

The focus of this paper is exterior fires in Swedish school buildings and the material presented is based on the results from a three-year project. The goal and purpose of the project has been to evaluate technical systems and engineering solutions to prevent and reduce the consequences of arson in school buildings. Early in the project it was concluded that a majority of the most costly fires begin with an exterior fire. Special attention has therefore been given to exterior fires in the project. Six different technical systems that can be used to mitigate the consequences of exterior fires have been evaluated with experiments, literature reviews and cost-benefit analysis.

The conducted experimental work has contributed significantly to the novelty of the project. Firstly, the experimental work on the intumescent system, among other things, highlights the importance of the behavior of classified products in realistic fire environments. This is essential with regard to performance-based design where analyses of the fire protection systems in the building relative to a probable worst-case or realistic fire are important. Secondly, the real scale outdoor experiments provided important experimental data and a clear indication of the significance of weather conditions, especially wind speed and wind direction, as these have a large influence on the experimental results. This possible variability, dependent on weather conditions, is something that designers need to consider when designing the protection against exterior fires.

Another important piece in the evaluation of the technical systems is the cost-benefit analysis. The cost of systems varies, as does the frequency of arson between different cities and schools; therefore, it is not possible to give a general recommendation on a national level. However, in areas with a high arson frequency most systems can be justified. There are several obvious uncertainties in the estimated cost-benefit ratios but they give ballpark figures and a ranking of the different systems that is considered to be applicable.

The research presented in this paper has been conducted within a multidisciplinary project initiated by The Swedish Fire Research Board (Brandforsk) in 2007. This project is financed by The Swedish Civil Contingencies Agency, The City of Malmö, Svenska Kommun Försäkrings AB, Kommunassurans Syd, Länsförsäkringar, Trygg-Hansa, Göta Lejon, St Eriks försäkring, Stockholmsregionens Försäkrings AB, Förenade Småkommuners Försäkringsbolag and KommuneForsikring which is gratefully acknowledged. The Crafoord Foundation, which has financed parts of this work, is also gratefully acknowledged. The authors would also like to thank all the coauthors in the different project reports, peer-reviewed papers and conference papers that are a part of this research project. 


\section{MATEC Web of Conferences}

\section{References}

[1] Simonson McNamee, M., Anlagd brand - ett stort samhällsproblem [Arson - A Large Sociatal Problem], report 2007:21, SP Technical Research Institute of Sweden, Borås, Sweden, 2007.

[2] van Hees, P \& and Johansson, N., "Use Of Case Studies To Determine Technical Deficiencies With Respect To Fire Spread In School Buildings," 12th International Interflam Conferance, vol. 2. Interscience Communications, Nottingham, England, pp. 1811-1816, 2010.

[3] Klason, L-G., Andersson, P., Johansson, N., \& van Hees, P., "Design Fires for Fire Protection Engineering of Swedish School Buildings", in Fire and Materials Conferance, 2011, pp. 159170.

[4] Johansson, N., van Hees, P., Simonson McNamee, M., \& Strömgren, M., "A Cost-Benefit Analysis of Fire Protection Systems Designed to Protect Against Exterior Arson Fires in Schools," in 9th International Conferance on Performance Based Codes and Fire Safety Design Methods, 2012.

[5] Johansson, N., Wahlqvist, J. \& van Hees, P., "Detection of a Typical Arson Fire Scenario Comparison Between Experiments and Simulations," Journal of Fire Protection Engineering, vol. 22, no. 1, pp. 23-44, Dec. 2012.

[6] Johansson, N., van Hees, P., McNamee Simonson, M., Andersson, P., Jansson, R. and Strömgren, M., "Technical Measures to Prevent and Mitigate the Concequences of Arson in School Buildings" submitted to the 11th International Symposium on Fire Safety Science, Christchurch, New Zeeland, 2014.

[7] Boverket, "Boverkets byggregler." Karlskrona, Sweden, 2011.

[8] Johansson N. \& Klason, L-G., Inventering av tekniska system avsedda att förebygga och begränsa konsekvenser av anlagd brand i skolor och förskolor, [Inventory of technical system to prevent and mitigate consequences of arson fires in schools and kindergartens], report 7033, Department of Fire Safety Engineering and System Safety, Lund University, Lund, Sweden, 2011.

[9] Andersson, P., Persson, H. \& Tuovinen, H.., Råd för installation av värmedetektionskablar på ytterfasad,[Advice for installing heat detection cables on façades], report 2006:09, SP Swedish National Testing and Reserach Institute, Borås, Sweden, 2006.

[10] Johansson, N. \& van Hees, P., Detektering av utvändiga bränder - Resultat från små- och stors- kaliga experiment [Detection of External Fires - Results from Small- and Real-Scale Experiments], Department of Fire Safety Engineering and System Safety, Lund University, Lund, Sweden, 2012.

[11] Johansson, N., Strömgren, M. \& van Hees, P., Anlagd brand Analys av kostnader och nyttor med tekniska system [Arson -An analysis of costs and benefits of technical systems], report 3171, Department of Fire Safety Engineering and System Safety, Lund University, Lund, Sweden, 2013.

[12] Johansson, N., van Hees, P., Jansson, R. \& Sjöström, J., "Behaviour of an Intumescing System Subjeted to Different Heating Conditions," Fire and Materials Conferance. San Fransisco, USA, 2013.

[13] Adl-Zarrabi, B., Influence of temperature, moisture, salt, cleaner compounds and rainwater on the expansion of intumescent fire seal, report 2007:80, SP Technical Research Institute of Sweden, Borås, Sweden, 2007.

[14] European Standards Organisation, Fire resistance tests for service installations - Part 4: Linear joint seals, European Standard EN 1366-4:2006 + A1, 2006.

[15] International Standards Organization, Fire Resistance Tests - Elements of Building Construction - Part 1: General Requirements, ISO 834-1, Geneva, Switzerland, 1999.

[16] van Hees, P., \& Johansson, N., Fallstudier - Vilka tekniska faktorer spelar en roll vid anlagd brand i skolor? [Case studies - Which technical properties play a role with arson fires in schools?], report 3148, Department of Fire Safety Engineering and System Safety, Lund University, Lund, Sweden, 2009. 
$1^{\text {st }}$ International Seminar for Fire Safety of Facades, Paris (France), 2013

[17] Klason, L-G., Johansson, N. \& P. Andersson, Dimensionerande brand: anlagda skolbränder [Design fires: arson in school buildings], report 2010:15, SP Technical Research Institute of Sweden, Borås, Sweden, 2010.

[18] N. Johansson, P. van Hees, M. S. McNamee, and M. Strömgren, Tekniska system för att förhindra och förebygga anlagd brand - Slutrapport [Technical systems to prevent and mitigate the consequences of arson- Final report], report 3170, Department of Fire Safety Engineering and System Safety, Lund University, Lund, Sweden, 2013. 